The Journal of Animal \& Plant Sciences, 31(3): 2021, Page: 862-867

ISSN (print): 1018-7081; ISSN (online): 2309-8694

\title{
EVALUATION OF ANTI-INFLAMMATORY, ANALGESIC AND ANTIPYRETIC ACTIVITIES OF SALSOLA IMBRICATA FORSSK IN RATS
}

\author{
K. H. Janbaz ${ }^{1}$, N. Aslam ${ }^{1 *}$, I. Imran ${ }^{1}$ and Q. Jabeen ${ }^{2}$ \\ ${ }^{1}$ Department of Pharmacology, Faculty of Pharmacy, Bahauddin Zakariya University, Multan, Pakistan \\ ${ }^{2}$ Department of Pharmacy, Faculty of Pharmacy and Alternative Medicine, the Islamia University of Bahawalpur, \\ Pakistan \\ *Author for correspondence, email: naveedbwppk@yahoo.com
}

\begin{abstract}
Salsola imbricata has folkloric repute in the treatment of painful and inflammatory conditions. Therefore, present study was undertaken to assess the anti-inflammatory, analgesic and antipyretic activities of aqueous-ethanol crude extract of S. imbricata (Si.Cr) using models of carrageenan-induced paw edema, $4 \% \mathrm{NaCl}$-mediated abdominal writhing, formalininduced paw licking and brewer's yeast-mediated pyrexia in rats. The $\mathrm{Si} . \mathrm{Cr}(100,300$ and $500 \mathrm{mg} / \mathrm{kg}$, p.o.) significantly $(p<0.001)$ inhibited carrageenan-induced paw edema in rats as compared to the saline treated control group. It inhibited writhes induced by intraperitoneal injection of $4 \% \mathrm{NaCl}(p<0.001)$ as compared to the control group. In the first phase of formalin-induced paw licking test, Si.Cr (100 and $300 \mathrm{mg} / \mathrm{kg}$ ) did not cause significant inhibition of nociception in rats, but at the dose of $500 \mathrm{mg} / \mathrm{kg}$, it produced significant $(p<0.05)$ reduction in time of licking paw by rats. Oral administration of Si.Cr $(100,300$ and $500 \mathrm{mg} / \mathrm{kg})$ reduced time of licking paw during the second phase of the formalin test. In addition, Si.Cr exhibited significant $(p<0.001)$ antipyretic activity in brewer's yeast-induced pyrexia in rats. This study, showing the presence of anti-inflammatory, analgesic and antipyretic activities in $\mathrm{Si}$.Cr, supports uses of the plant in folk medicine.
\end{abstract}

Key words: Chenopodiaceae; carrageenan; formalin test; $\mathrm{NaCl}$ writhing test; yeast induced pyrexia.

https://doi.org/10.36899/JAPS.2021.3.0276

Published online November 20, 2020

\section{INTRODUCTION}

Inflammation, pain and fever are important components of the innate defense system. These responses are complex in nature and usually exist in many conditions, like infections, rheumatic disorders, diabetes, cardiovascular diseases and cancers (Narumiya and Furuyashiki, 2011; Scrivo et al., 2011). Non-steroidal anti-inflammatory drugs (NSAIDs) are commonly used drugs that have the property of concomitantly mitigating inflammation, pain and fever. But these drugs are associated with severe gastrointestinal and cardiovascular side effects (Steinmeyer, 2000).

In the history of mankind, plants were first curatives. In many developing countries, alternative medicine is an only affordable and accessible way to meet the healthcare needs of the majority of the population. In developed countries, the use of phytomedicine is also at increase due to the general belief of being more effective, safer and economical than the conventional drugs. However, issues regarding justification for such claims are often discussed among scientific community (Eardley et al., 2012).

Salsola imbricata Forssk (synonyms: Salsola baryosma Schult. $=$ Salsola foetida Del. $=$ Chenopodium baryosmum Schult. = Caroxylon foetidum Moquin.) belongs to family Chenopodiaceae. The plant is distributed throughout warm desert areas of northwest India, Pakistan, Iran, Afghanistan and tropical east Africa (Boulos, 1991). It has folkloric repute in the treatment of various diseases like indigestion, diarrhea, dysentery, cold, asthma, migraine, headache and inflammations (Handa et al. 2006; Ahmed et al., 2014; Malik et al., 2015; Phondani et al., 2016). Phytochemicals belonging to classes of alkaloids, anthraquinones, tannins, saponins and flavonoids are described in S. imbricata extracts (Hamed et al., 2011; Munir et al,. 2014). Scientific studies revealed that it has antioxidant, smooth muscle relaxant (Ahmed et al., 2006; Aslam and Janbaz, 2017), contraceptive (Shehab and Abu-Gharbieh, 2014), antibacterial (Kaur and Banas, 2004), tyrosinase (Khan et al., 2003) and butyrylcholinesterase inhibitory (Ahmed et al., 2007) activities. The methanol extract of its leaves and isolated compounds; Isorhamnetin, Isorhamnetin glucosides and trans $\mathrm{N}$-feruloyl tyramine have been found to possess potent inhibitory effect on lipopolysaccharide-induced nitric oxide release in isolated macrophages, indicating potential antiinflammatory activity of the plant (Osman et al., 2016).

To the best of our knowledge, no scientific evidence is available in the literature to support the analgesic and antipyretic activities of the plant. Only one study reported in vitro anti-inflammatory activity of the plant (Osman et al., 2016). Therefore, anti-inflammatory, 
analgesic and antipyretic activities of aqueous-ethanol extract of $S$. imbricata were evaluated using rat models in this study.

\section{MATERIALS AND METHODS}

Plant material: Aerial parts of $S$. imbricata were collected from an area of Cholistan desert, Punjab, Pakistan during the month of May 2014. A specimen sample of the collected plant material (voucher number Fl.P.225-9) was deposited in the herbarium of the institute subsequent to identification by Prof. Dr. Altaf Ahmed Dasti, plant taxonomist, Institute of Pure and Applied Biology, Bahauddin Zakariya University, Multan, Pakistan.

Extraction: The aerial parts of $S$. imbricata were shade dried for 14 days, converted into coarse powder using an electric grinder and extracted with aqueous-ethanol $(30: 70 \mathrm{v} / \mathrm{v})$ by process of maceration at ambient temperature for 72 hours and filtered. Maceration of the marc with fresh solvent was repeated twice more, all three filtrates were combined and subjected to evaporation in rotary evaporator (Rotavapor, Buchi, Switzerland) under reduced pressure at $37^{\circ} \mathrm{C}$ to obtain Salsola imbricata crude extract ( $\mathrm{Si} . \mathrm{Cr}$ ). The percentage yield of Si.Cr was 8.60 and stored at $-4^{\circ} \mathrm{C}$ until used (Aslam and Janbaz, 2017). The required dose of Si.Cr was dissolved in normal saline for oral administration to rats in a volume of $10 \mathrm{ml} / \mathrm{kg}$.

Animals: Sprague Dawley rats (both sexes, 150-180 g), kept at animal house of the Faculty of Pharmacy, Bahauddin Zakariya University Multan, Pakistan at controlled conditions of temperature and light $\left(25 \pm 2{ }^{\circ} \mathrm{C}\right.$; 12 hours light-dark intervals) were used. The animals were fed with a standard diet and had free access to drinking water. With the exception of antipyretic activity, the diet was withdrawn 12 hours before starting experiments. The "Guide for the Care and Use of Laboratory Animals" issued by National Research Council (2011) was met with and use of animals in the study was allowed by the Ethical Committee of the Institution (approval No. 02-PhDL/13).

Drugs and chemicals: All the chemicals were of biochemical and research grade. Carrageenan, formalin and aspirin were procured from Sigma-Aldrich Chemicals Co. USA. $\mathrm{NaCl}$ was purchased from $\mathrm{BDH}$, UK. Brewer's yeast (Heilongjinag Jiuding Yeast Co. Ltd. China) was purchased from the local mart. Tramadol was made available from Searle Pakistan Pvt. Ltd. Karachi. All chemicals were dissolved in normal saline.

Anti-inflammatory activity: Method of carrageenaninduced hind paw inflammation was used (Lee et al., 2012). Rats were randomized into five groups containing six animals in each group. The control group was treated orally with normal saline $(10 \mathrm{ml} / \mathrm{kg})$. The standard group received aspirin $(100 \mathrm{mg} / \mathrm{kg})$, while three treatment groups received $\mathrm{Si} . \mathrm{Cr}$ at oral doses of 100, 300 and 500 $\mathrm{mg} / \mathrm{kg}$. After 1 hour, $0.1 \mathrm{ml}$ of carrageenan (1\%) was injected into the left hind paw plantar surface by using $27 \mathrm{G}$ needle. Immediately after injection, the volume of the paw was measured using plethysmometer (Ugo Basile, Milan, Italy). Subsequently, paw volumes were again measured at hourly intervals for four hours. The mean change in the paw volume was calculated with respect to the initial paw volume.

\section{Analgesic activity}

Formalin-induced paw licking: Rats were randomized into six groups of six animals each. The control group was administered normal saline $(10 \mathrm{ml} / \mathrm{kg})$; the reference group was given aspirin $(100 \mathrm{mg} / \mathrm{kg})$ and test groups received Si.Cr at doses of 100, 300 and $500 \mathrm{mg} / \mathrm{kg}$, orally. Another reference group received tramadol $(10 \mathrm{mg}$ $/ \mathrm{kg})$. After 1 hour, formalin $(0.1 \mathrm{ml} ; 2.5 \%)$ was injected into the dorsal surface of the right hind paw of each rat using $27 \mathrm{G}$ needle. Rats were then observed individually after placing in glass observation chambers. The time spent in biting and licking the injected paw was measured and recorded for (first phase) 0-5 minutes and (second phase) 15-30 minutes (Vogel, 2008).

$\mathrm{NaCl}$-induced writhing: Rats were randomized into five groups of six animals each. Rats of the control group were given normal saline $(10 \mathrm{ml} / \mathrm{kg}$, p.o. $)$. The standard group received aspirin $(100 \mathrm{mg} / \mathrm{kg}$, p.o.). Three treatment groups received $\mathrm{Si} . \mathrm{Cr}$ at respective doses of 100, 300 and $500 \mathrm{mg} / \mathrm{kg}$, orally. After 1 hour, $\mathrm{NaCl}(4 \%, 0.3 \mathrm{ml}$, i.p.) was injected and animals were individually placed in glass observation chambers to count numbers of writhing for 3 minutes (Fukawa et al., 1980; Vogel, 2008; Kaur and Silakari, 2018).

Antipyretic Activity: The method of brewer's yeast caused fever in rats, was used (Khan et al., 2013). The rectal temperature of rats was recorded using an electronic clinical thermometer. $20 \%$ suspension of brewer's yeast in normal saline was injected $(10 \mathrm{~m} / \mathrm{kg}$, s.c.) below the nape of the neck. Food was withdrawn during the experiment. Eighteen hours after yeast injections, rats showing $0.5-1.5^{\circ} \mathrm{C}$ elevation in rectal temperature were grouped for respective oral treatments. The control group was given normal saline $(10 \mathrm{ml} / \mathrm{kg}$, p.o.); while experimental groups received $\mathrm{Si} . \mathrm{Cr}$ at oral doses of 100,300 and $500 \mathrm{mg} / \mathrm{kg}$. Aspirin $(150 \mathrm{mg} / \mathrm{kg}$, p.o.) was given to the reference group. After that, hourly recordings of rectal temperature were taken for five hours.

Statistical analysis: Values are presented as mean \pm standard error of mean (SEM). Treatment and standard 
groups were compared with their respective saline treated controls using analysis of variance followed by Bonferroni post tests. GraphPad Prism Software (GraphPad, USA) was used to construct graphs and analyze data. $p<0.05$ was considered significant.

\section{RESULTS}

Anti-inflammatory activity of Si.Cr: In the experimental model of carrageenan-induced paw edema in rats, oral administration of Si.Cr at doses of 100, 300 and 500 $\mathrm{mg} / \mathrm{kg}$ resulted significant $(\mathrm{p}<0.001)$ inhibition of paw edema in a dose dependent manner after 2 hours of carrageenan injections as compared to the normal saline treated control group. The standard drug aspirin also showed significant $(\mathrm{p}<0.001)$ inhibition of paw edema after 2 hours of carrageenan injections versus the control group (Table 1).

Analgesic activity of Si.Cr: When $4 \% \mathrm{NaCl}$ was injected into the peritoneal cavity to induce writhing in rats, a decrease in the number of writhing was observed following oral administration of $\mathrm{Si} . \mathrm{Cr}$ in a dose dependent manner $(100-500 \mathrm{mg} / \mathrm{kg})$. Treatment with aspirin $(100 \mathrm{mg} / \mathrm{kg})$ also decreased $(p<0.001)$ number of writhing induced by $4 \% \mathrm{NaCl}$, when compared to the normal saline treated control group (Fig. 1).

In formalin-induced paw licking test, time spent in licking paw following formalin injection during the first phase was reduced after oral treatments with tramadol $(p<0.001)$ and Si.Cr at $500 \mathrm{mg} / \mathrm{kg}(p<0.01)$, while remained unaffected in groups treated with aspirin $(100 \mathrm{mg} / \mathrm{kg})$ and lower doses of Si.Cr (100 and 300 $\mathrm{mg} / \mathrm{kg}$ ). During second phase, all treatments significantly inhibited the time spent in licking paw compared to the saline treated control as shown in Fig. 2.

Antipyretic activity of Si.Cr: In the experimental model of brewer's yeast-induced pyrexia in rat, oral treatments with Si.Cr $(100,300$ and $500 \mathrm{mg} / \mathrm{kg})$ significantly $(p<0.001)$ reduced the rectal temperature during the observation period of 5 hours in comparison with the control group as shown in Fig. 3. The standard drug aspirin $(150 \mathrm{mg} / \mathrm{kg})$ also produced significant $(p<0.001)$ antipyretic response versus the control during the observation period.

Table 1. Effects of various doses of crude extract of $S$. imbricata (Si.Cr), aspirin and normal saline on carrageenan-induced paw edema in rats.

\begin{tabular}{lcccc}
\hline \multirow{2}{*}{ Treatments } & \multicolumn{3}{c}{ \% Increase in paw volume after carrageenan injection } \\
\cline { 2 - 5 } & 1 hour & 2 hours & 3 hours & 4 hours \\
\hline Normal saline $(10 \mathrm{ml} / \mathrm{kg})$ & $49.7 \pm 3.6$ & $72.4 \pm 4.7$ & $78.4 \pm 3.5$ & $84.6 \pm 4.4$ \\
Aspirin $(100 \mathrm{mg} / \mathrm{kg})$ & $41.3 \pm 2.2$ & $16.6 \pm 2.7^{* * *}$ & $17.3 \pm 2.2^{* * *}$ & $17.1 \pm 2.2^{* * *}$ \\
Si.Cr $(100 \mathrm{mg} / \mathrm{kg})$ & $50.0 \pm 5.7$ & $47.7 \pm 5.1^{* * *}$ & $46.8 \pm 1.7^{* * *}$ & $45.9 \pm 9.4^{* * *}$ \\
Si.Cr $(300 \mathrm{mg} / \mathrm{kg})$ & $43.8 \pm 4.2$ & $32.6 \pm 3.7^{* * *}$ & $27.9 \pm 1.5^{* * *}$ & $19.6 \pm 3.7^{* * *}$ \\
Si.Cr $(500 \mathrm{mg} / \mathrm{kg})$ & $37.6 \pm 8.7$ & $21.1 \pm 7.7^{* * *}$ & $8.9 \pm 2.6^{* * *}$ & $7.4 \pm 1.3^{* * *}$ \\
\hline
\end{tabular}

All values are mean $\pm \operatorname{SEM}(\mathrm{n}=6),{ }^{* * *} p<0.001$ versus saline treated group.

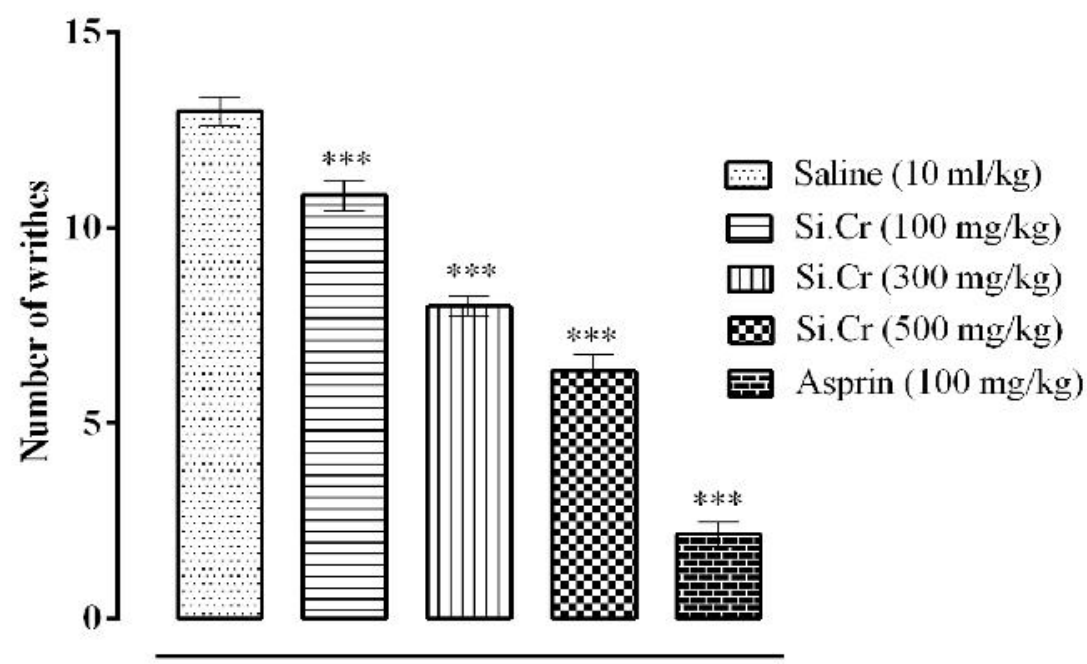

Fig. 1: Effects of various doses of crude extract of $S$. imbricata (Si.Cr), aspirin and normal saline on $4 \%$ NaClinduced writhing in rats. All values are mean $\pm \operatorname{SEM}(n=6),{ }^{* * * *} \mathbf{p}<0.001$ versus saline treated group. 


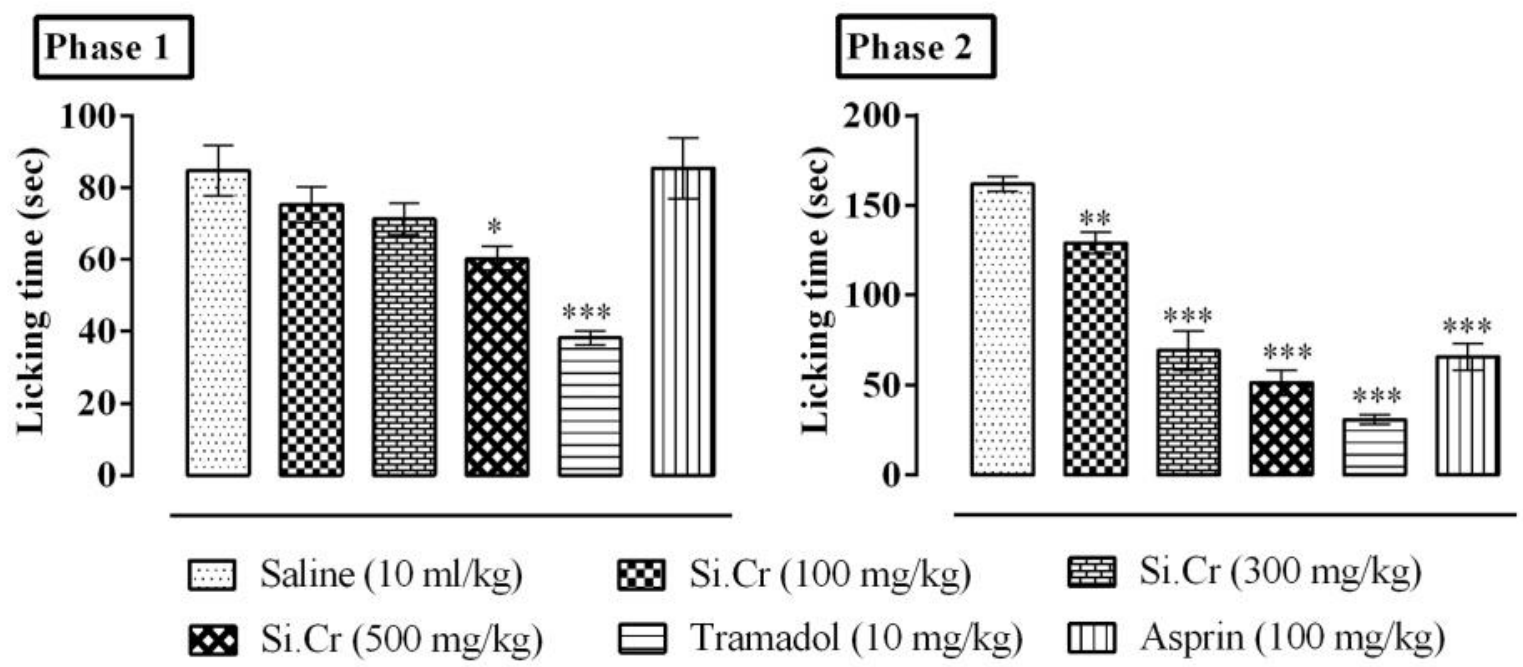

Fig. 2: Effects of various doses of crude extract of $S$. imbricata (Si.Cr), aspirin, tramadol and normal saline on formalin-induced paw licking in rats. All values are mean $\pm \operatorname{SEM}(\mathbf{n}=6),{ }^{*} \mathbf{p}<0.05,{ }^{* *} \mathbf{p}<0.01,{ }^{* * *} \mathbf{p}<0.001$ versus saline treated group.

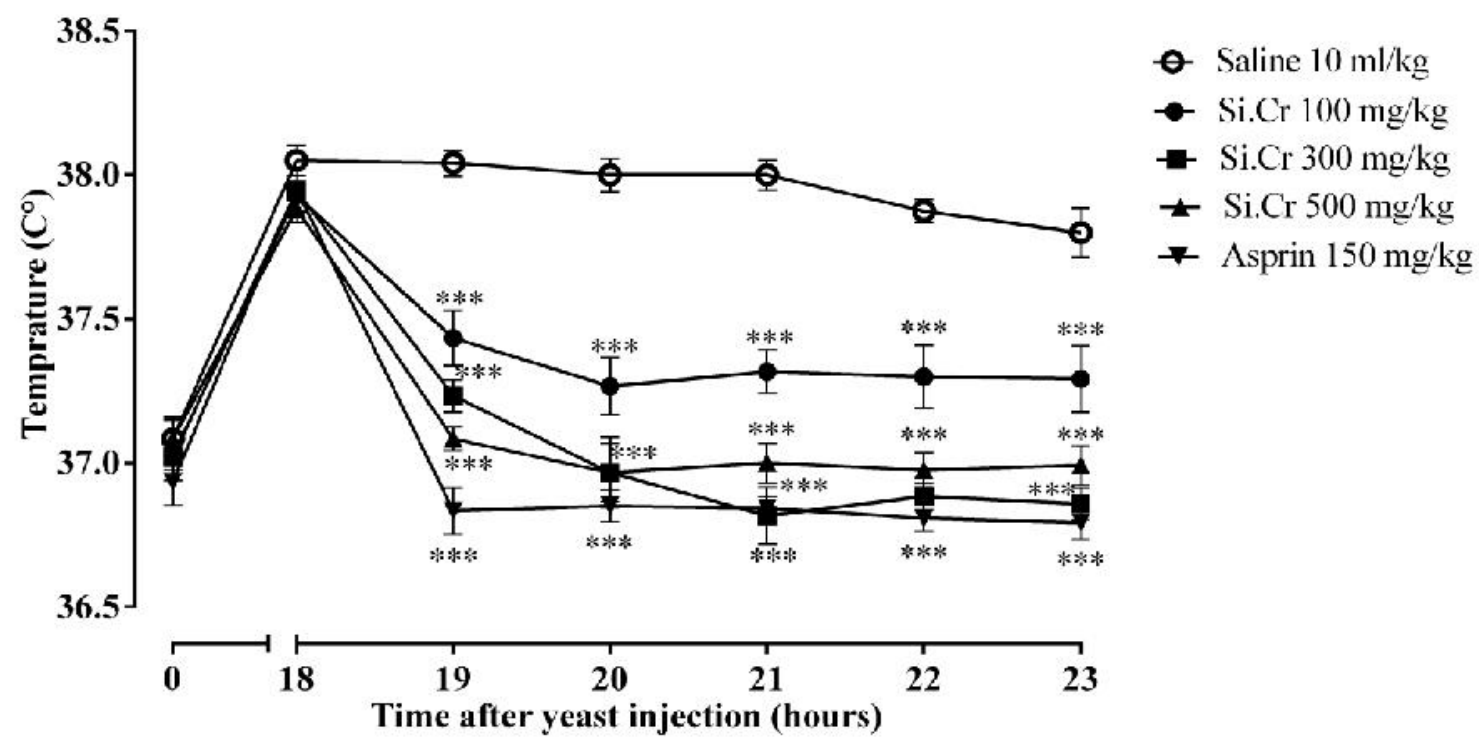

Fig. 3: Effects of various doses of crude extract of $S$. imbricata (Si.Cr), aspirin and normal saline on brewer's yeast-induced pyrexia in rats. All values are mean $\pm \operatorname{SEM}(n=6),{ }^{* * *} p<0.001$ versus saline treated group.

\section{DISCUSSION}

In view of the alternative medicinal uses of $S$. imbricata in painful and inflammatory conditions, the $\mathrm{Cd} . \mathrm{Cr}$ was studied for possible anti-inflammatory, analgesic and antipyretic activities in rat animal model. Carrageenan-mediated paw edema in rodents is a classical and widely used model of inflammation, which involves the release of several inflammatory molecules in a sequential manner. Serotonin, histamine and bradykinin appear first in carrageen induced edema, whereas prostaglandins (PGs) appear in the late episode. Levels of pro-inflammatory cytokinins and free radicals are also increased during the late episode of inflammation. The initial phase of inflammation is not usually inhibited by NSAIDs (Al-Swayeh et al., 2000; Necas and Bartosikova, 2013). As oral administration of Si.Cr attenuated inflammation during the late episode of carrageenan-induced hind paw edema, therefore, the $\mathrm{Cd} . \mathrm{Cr}$ may be considered to have an inhibitory effect on release or generation of chemical mediators of the late stage of inflammation. Our finding regarding in vivo antiinflammatory activity of Si.Cr in rats is in support and agreement with the already published work on in vitro 
anti-inflammatory potential of $S$. imbricata extract and isolated compounds (Osman et al., 2016).

To study the analgesic effect of $\mathrm{Si}$. $\mathrm{Cr}$, hypertonic solution of $4 \% \mathrm{NaCl}$ was injected into the peritoneal cavity of rats to induce writhing. High cationic concentration is able to sensitize transient receptor potential vanilloid type 1 (TRPV1) receptors to induce visceral pain (Ahern et al., 2005). Narcotic and nonnarcotic analgesics can be evaluated even at low doses by this method (Fukawa et al., 1980). A significant reduction in writhing with $\mathrm{Si} . \mathrm{Cr}$ at all doses was observed, indicating its good analgesic activity in visceral pain.

The formalin method is a widely used for evaluation of analgesic activity in animals that allow distinguishing between central and peripheral mechanisms of action of analgesia. Injecting formalin into hind paw of rats induce biphasic pain, which can be evaluated by measuring the time of licking and biting the injected paw during both phases (Vogel, 2008). The first phase (0-5 minutes), called neurogenic phase, results from direct activation of pain fibers by local release of pain mediators, such as substance $P$, bradykinin, glutamate etc. Whereas second intense phase (15-30 minutes), called the inflammatory phase, results from release of inflammatory mediators of arachidonic acid metabolism and free radicals, which cause direct activation of pain receptors and central sensitization of pain in dorsal horn (Barrot, 2012). The results of our investigations revealed that $\mathrm{Si}$. $\mathrm{Cr}$, at 100 and $300 \mathrm{mg} / \mathrm{kg}$ doses, was effective in the inflammatory phase only, indicating that it has primarily peripheral analgesic activity. At the high dose of $500 \mathrm{mg} / \mathrm{kg}$, it inhibited both phases, indicating the involvement of central and peripheral mechanisms in its analgesic activity. Reference drug aspirin inhibited pain during the inflammatory phase only. Tramadol was also used as reference drug in our study, which inhibited both phases of formalin induced pain. Tramadol produced central analgesia by opioid ( $\mu$-agonistic) and non-opioid (inhibition of monoamine uptake) mechanisms (Bravo et al., 2017).

As most of the non-narcotic analgesic and antiinflammatory drugs also possess antipyretic action, therefore, $\mathrm{Si}$. $\mathrm{Cr}$ was tested for antipyretic activity. A peripheral inflammatory response causes an increase in circulating prostaglandin- $\mathrm{E}_{2}\left(\mathrm{PGE}_{2}\right)$, which activates local sensory vagal terminals conveying signals to nucleus tractus solitaries. From there, adrenergic fibers transmit signals to ventromedial preoptic area (VMPO) resulting in a rapid onset $\alpha_{1}$-mediated increase in core body temperature followed by a delayed onset $\alpha_{2}$-mediated increase in cyclooxygenase-2-dependent-PGE 2 synthesis in VMPO by elevating set point to thermo-regulation. Nitric oxide acts as a modulator to the effects of $\mathrm{PGE}_{2}$ in the periphery and CNS (Blatteis, 2007). Most antipyretic drugs work by decreasing $\mathrm{PGE}_{2}$ formation via inhibition of enzyme cyclooxygenase. Other mechanism such as decrease in pro-inflammatory mediators, increase in antiinflammatory signaling at the site of injury or boosting antipyretic messages in CNS may also contribute in analgesic activity of drugs (Aronoff and Neilson, 2001). Si. Cr has shown significant antipyretic activity in yeastinduced pyrexia in rats, which may be co-related to its analgesic and anti-inflammatory actions. Previous studies reported that antioxidants possess analgesic and antiinflammatory activities (Kim et al., 2012). The observed analgesic, anti-inflammatory and antipyretic activities of Si.Cr may be due to the presence of antioxidant phytochemicals in the plant (Munir et al., 2014; Shehab and Abu-Gharbieh, 2014) and inhibition of lipopolysaccharide-induced nitric oxide release from macrophages (Osman et al., 2016). However, further studies are required to find out the exact mode of action of $\mathrm{Si} . \mathrm{Cr}$ for its anti-inflammatory, analgesic and antipyretic activities.

On the basis of these results, it is concluded that the crude extract of $S$. imbricata possesses antiinflammatory, analgesic and antipyretic activities in animal model, which provides scientific justification for use of the plant in folk medicine.

Acknowledgements: The authors are thankful to Prof. Dr. Altaf Ahmed Dasti, Institute of Pure and Applied Biology, BZ University, Multan, Pakistan for authenticating the collected plant material.

\section{REFERENCES}

Ahern, G.P., I.M. Brooks, R.L. Miyares, and X.B.Wang (2005). Extracellular cations sensitize and gate capsaicin receptor TRPV1 modulating pain signaling. J. Neurosci., 25(21): 5109-5116.

Ahmed, N., A. Mahmood, S.S.Tahir, A. Bano, R.N. Malik, S. Hassan, and A. Ashraf (2014). Ethnomedicinal knowledge and relative importance of indigenous medicinal plants of Cholistan desert, Punjab province, Pakistan. J. Ethnopharmacol., 155(2): 1263-1275.

Ahmed, S., M. Ashraf, A. Jabbar, K.H. Janbaz, M.S. Khan, A.H. Gilani, and M.I. Choudhary (2006). Pharmacological screening of Salsola baryosma. J. Chem. Soci. Pakistan, 28(1): 82-83.

Ahmed, Z., S. Mehmood, R. Ifzal, A. Malik, N. Afzal, F. Rashid, A. Mehmood, and L. Iqbal (2007). Butyrylcholinesterase inhibitory triterpenes from Salsola baryosma. Pol. J. Chem., 81(8): 14271432.

Al-Swayeh, O., R. Clifford, P.D. Soldato, and P. Moore (2000). A comparison of the anti-inflammatory and anti-nociceptive activity of nitroaspirin and aspirin. Br. J. Pharmacol., 129(2): 343-350. 
Aronoff, D.M., and E.G. Neilson (2001). Antipyretics: mechanisms of action and clinical use in fever suppression. Am. J. Med., 111(4): 304-315.

Aslam, N., and K.H. Janbaz (2017). Antispasmodic and bronchorelaxant activities of Salsola imbricata are mediated through dual $\mathrm{Ca}^{+2}$ antagonistic and $\beta$-adrenergic agonistic effects. Pharm. Biol., 55(1): 1131-1137.

Barrot, M. (2012). Tests and models of nocioception and pain in rodents. Neuroscience, 211: 39-50.

Blatteis, C.M. (2007). The onset of fever: new insights into its mechanism. Prog. Brain Res., 162: 3-14.

Boulos, F. (1991). The identity, typification and distribution of Salsola imbricata Forsskal. Kew Bull., 46: 137-140.

Bravo, L., J.A. Mico, and E. Berrocoso (2017). Discovery and development of tramadol for the treatment of pain. Expert Opin. Drug Disc., 12(12): 12811291.

Eardley, S., F.L. Bishop, P. Prescott, F. Cardini, B. Brinkhaus, K. Santos-Rey, J. Vas, K. von Ammon, G. Hegyi, and S. Dragan (2012). A systematic literature review of complementary and alternative medicine prevalence in EU. Forsch. Komplementmed., 19(suppl. 2): 18-28.

Fukawa, K., O. Kawano, M. Hibi, N. Misaki, S. Ohba, and Y. Hatanaka (1980). A method for evaluating analgesic agents in rats. J. Pharmacol. Methods, 4(3): 251-259.

Hamed, A.I., M. Masullo, M.G. Sheded, U.A. Mahalel, M.M. Tawfik, A. Perrone, and S. Piacente (2011). Triterpene saponins from Salsola imbricata. Phytochem. Lett., 4(3): 353-356.

Handa, S.S., D.D. Rakesh, and K. Vasishat (2006). Compendium of medicinal and aromatic plantsAsia (II), Earth, Enviornmental and Marine Sciences and Technologies. ICS-UNIDO; Italy. 223-282 pp.

Kaur, G., and O. Silakari (2018). Benzimidazole scaffold base hybrid molecules for various inflammatory targets: synthesis and evaluation. Bioorg. Chem., 80: 24-35.

Kaur, P., and N.S. Banas (2004). Extraction of flavonoids from in vivo and in vitro tissue culture of some important halophyes of western Rajasthan. Int. J. Pharm. Tech. Res., 4(3): 1167-1171.

Khan, H., M. Saeed, A.H. Gilani, N. Muhammad, I.U. Haq, N. Ashraf, N.U. Rehman, and A. Haleemi (2013). Antipyretic and anticonvulsant activity of Polygonatum verticillatum: comparison of rhizomes and aerial parts. Phytother. Res., 27(3): 468-471.

Khan, K.M., G.M. Maharvi, A. Abbaskhan, S. Hayat, M.T.H. Khan, T. Makhmoor, M.I. Choudhary, and F. Shaheen (2003). Three tyrosinase inhibitors and antioxidant compounds from
Salsola foetida. Helvetica Chimica Acta, 86(2): 457-464.

Kim, M.J., B.H. Hong, E.J. Zhang, Y.K. Ko, and W.H. Lee (2012). Antinociceptive effects of intraperitoneal and intrathecal vitamin $\mathrm{E}$ in the rat formalin test. Korean J. Pain, 25(4): 238-244.

Lee, M.H., H.M. Choi, D.H. Hahm, E. Her, H.I. Yang, M.C. Yoo, and K.S. Kim (2012). Analgesic and anti-inflammatory effects in animal models of an ethanolic extract of Taheebo, the inner bark of Tabebuia avellanedae. Mol. Med. Rep., 6(4): 791-796.

Malik, S., S. Ahmad, A. Sadiq, K. Alam, H.M. Wariss, I. Ahmad, M.Q. Hayat, S. Anjum, and M. Mukhtar (2015). A comparative ethno-botanical study of Cholistan (an arid area) and Pothwar (a semiarid area) of Pakistan for traditional medicines. J. Ethnobiol. Ethnomed., 11: 31.

Munir, U., A. Perveen, and S. Qamarunnisa (2014). Comparative Pharmacognostic evaluation of some species of the genera Suaeda and Salsola leaf (Chenopodiaceae). Pakistan J. Pharm. Sci., 27(5): 1309-13015.

Narumiya, S., and T. Furuyashiki (2011). Fever, inflammation, pain and beyond: prostanoid receptor research during these 25 years. FASEB J., 25(3): 813-818.

Necas, J., and L. Bartosikova (2013). Carrageenan: a review. Vet. Med., 58(4): 187-205.

Osman, S.M., W.A. El-Kashak, M. Wink, and M.A. ElRaey (2016). New isorhamnetin derivatives from Salsola imbricata Forssk. leaves with distinct anti-inflammatory activity. Pharmacogn. Mag., 12(Suppl 1): S47-S51.

Phondani, P.C., A. Bhatt, E. Elsarrag, and Y.A. Horr (2016). Ethnobotanical magnitude towards sustainable utilization of wild foliage in Arabian desert. J. Traditional Complementary Med., 6(3): 209-218.

Scrivo, R., M. Vasile, I. Bartosiewicz, and G. Valesini (2011). Inflammation as "common soil" of the multifactorial diseases. Autoimmun. Rev., 10(7): 369-374.

Shehab, N.G., and E. Abu-Gharbieh (2014). Phenolic profiling and evaluation of contraceptive effect of the ethanolic extract of Salsola imbricata Forssk. in male albino rats. Evid. Based Complement. Alternat. Med., 2014: 695291.

Steinmeyer, J. (2000). Pharmacological basis for the therapy of pain and inflammation with nonsteroidal anti-inflammatory drugs. Arthritis Res. Ther., 2(5): 1-7.

Vogel, H. (2008). Drug Discovery and Evaluation: Pharmacological Assays, $3^{\text {rd }}$ Ed. SpringerVerlage; Berlin Heidelberg.1020-1031 pp. 